top acropolis site at the head of the delta, where surface finds on one hand match the pottery of various periods at Tell Sheikh Yusuf, and on the other include fragments of Mycenæan and Cypriote bronze age wares corresponding with the later levels of Tell Atchana.

\section{Recent Acquisitions at the Natural History Museum}

Mrs. Constance Thorburn has presented to the Department of Zoology of the Museum seventeen water-colour drawings of British mammals executed by her husband the late Archibald Thorburn. Purchases for the Department include a collection of small mammals, mostly rodents, including some rare and little-known species from the Cameroons; and a small collection of European birds obtained on their northward migration in April and May by Mr. C. G. Bird, at Rio d'Oro, on the north-east coast of Africa. Dr. C. T. Trechmann has generously presented to the Department of Geology a large and valuable collection (including more than 200 type and figured specimens) of Mollusca collected by him from the West Indies. The Mineral Department has received as a gift from Mr. Arthur Earland sea-bottom deposits collected from the Weddell Sea in the Antarctic by the "Discovery" expedition, together with the crystals of gypsum, calcium oxalate, and the new mineral earlandite which had been picked by him from the samples collected. Among the purchases is a series of minerals from Brazil, including a beautiful, table-cut, strongly dichroic aquamarine, spodumene of three kinds and quartz in many different forms and habits. A series of well-shaped crystals of lapis-lazuli and three iridescent limonites from Queensland also have been bought.

\section{Mathematics in Bombay}

A very interesting experiment in the teaching of mathematics is being carried out in the University of Bombay. Prof. John Maclean, of Wilson College, has had the commendable courage to break away from the beaten track of academic mathematics by devising a special course for his students, dealing mainly with the uses of elementary mathematical methods in the description of quantitative phenomena. The course forms the subject matter of a recent book by Prof. Maclean entitled "Descriptive Mathematics", which was noticed in Nature of March 7, p. 382. In the Bombay Intermediate Arts and Science examination in March, alternative papers were set; one being of the traditional academic type, whilst the other, entitled "Statistics and Nomograms", was designed to test the efficacy of the new course. Out of a total of 1,400 students, about twenty took this paper. Its questions cover a wide field, and range from Newton's interpolation formula, probability and frequency distributions to transcendental equations and the construction of various types of nomograms. It will be interesting to study the results of this experiment for, judged by the examination paper in conjunction with Prof. Maclean's book, the new course is certainly designed not only to stimulate interest, but also to render a rigorous presentation of the basic ideas in mathematics much more vivid and powerful than that provided by the stereotyped courses.

\section{Scientific Research in Australia}

THE ninth annual report of the Council for Scientific and Industrial Research, Commonwealth of Australia (Canberra: Government Printer, 1936. 4s. 8d.), covers the year ended June 30, 1935, and gives brief accounts of the work of the various divisions in which the work is organised. Weed problems are receiving a considerable share of attention, particularly on the entomological side, through the introduction and distribution of insects which attack the plants in other countries. Investigations are being initiated into contagious bovine mastitis, a serious disease prevalent in dairy herds throughout the world, and an attempt is being made to establish at a dairy farm near Melbourne a normal herd free from the disease. The rabbit pest and the testing of seeds continue to receive attention, and in addition to its investigations on weed pests, the Division of Economic Entomology has been investigating means of preventing the attack of sheep by blowflies. The Division of Animal Health has discovered new and more effective methods of administering anthelminties for the control of internal parasites of sheep, while the Division of Animal Nutrition has studied the 'coast disease' of sheep, drought feeding and the processes of wool growth. Soil problems, timber preservation and seasoning, the preservation and transport of fruit and chilled beef have been investigated by other Divisions. Even the brief accounts of these investigations contained in the present report indicate that the work of the Council is making noteworthy contributions to the welfare of the basic industries and occupations of Australia.

\section{Geological Survey of Australia}

WHEN the Commonwealth of Australia was established, the administration of mining affairs, including geological work, was left with the six independent States. The consequence is that Australia is to-day the only dominion without a national geological survey, a situation which is viewed with grave dissatisfaction by its scientific workers. Every effort hitherto made to remedy the position has failed owing to official opposition from some, but not all, of the State Departments of Mines. A conference between Commonwealth and State officers, held in Melbourne last month, was but little more successful than any of its predecessors. Political, rather than scientific, considerations appear to dominate the issue, and this further failure to agree upon the establishment of a national body, either by the Commonwealth alone or by the States acting jointly, is greatly to be regretted.

\section{Economic Products of the British Empire}

VoL. 34, No. 1 of the Bulletin of the Imperial Institute has been published by the Institute itself, but the general format remains practically unaltered. This number contains an important report by the 